\title{
Spinal neurovascular complications with anterior thoracolumbar spine surgery: a systematic review and review of thoracolumbar vascular anatomy
}

\author{
Nathan A. Shlobin, BA, ${ }^{1}$ Eytan Raz, MD, ${ }^{3}$ Maksim Shapiro, MD, ${ }^{3}$ Jeffrey R. Clark, BA, \\ Steven C. Hoffman, BS, ${ }^{1}$ Ali Shaibani, MD, ${ }^{1,2}$ Michael C. Hurley, MD,, 12 \\ Sameer A. Ansari, MD, PhD, ${ }^{1,2}$ Babak S. Jahromi, MD, PhD, ${ }^{1,2}$ Nader S. Dahdaleh, MD, ${ }^{1}$ \\ and Matthew B. Potts, MD1,2
}

\begin{abstract}
Departments of ${ }^{1}$ Neurological Surgery and ${ }^{2}$ Radiology, Northwestern University Feinberg School of Medicine, Northwestern Memorial Hospital, Chicago, Illinois; and ${ }^{3}$ Departments of Radiology and Neurological Surgery, New York University Grossman School of Medicine, Bernard and Irene Schwartz Neurointerventional Radiology Section, NYU Langone Medical Center, New York, New York
\end{abstract}

OBJECTIVE Spinal cord infarction due to interruption of the spinal vascular supply during anterior thoracolumbar surgery is a rare but devastating complication. Here, the authors sought to summarize the data on this complication in terms of its incidence, risk factors, and operative considerations. They also sought to summarize the relevant spinal vascular anatomy.

METHODS They performed a systematic literature review of the PubMed, Scopus, and Embase databases to identify reports of spinal cord vascular injury related to anterior thoracolumbar spine procedures as well as operative adjuncts and considerations related to management of the segmental artery ligation during such anterior procedures. Titles and abstracts were screened, and studies meeting inclusion criteria were reviewed in full.

RESULTS Of 1200 articles identified on the initial screening, 16 met the inclusion criteria and consisted of 2 prospective cohort studies, 10 retrospective cohort studies, and 4 case reports. Four studies reported on the incidence of spinal cord ischemia with anterior thoracolumbar surgery, which ranged from $0 \%$ to $0.75 \%$. Eight studies presented patient-level data for 13 cases of spinal cord ischemia after anterior thoracolumbar spine surgery. Proposed risk factors for vasculogenic spinal injury with anterior thoracolumbar surgery included hyperkyphosis, prior spinal deformity surgery, combined anterior-posterior procedures, left-sided approaches, operating on the concavity side of a scoliotic curve, and intra- or postoperative hypotension. In addition, eight studies analyzed operative considerations to reduce spinal cord ischemic complications in anterior thoracolumbar surgery, including intraoperative neuromonitoring and preoperative spinal angiography.

CONCLUSIONS While spinal cord infarction related to anterior thoracolumbar surgery is rare, it warrants proper consideration in the pre-, intra-, and postoperative periods. The spine surgeon must be aware of the relevant risk factors as well as the pre- and intraoperative adjuncts that can minimize these risks. Most importantly, an understanding of the relevant spinal vascular anatomy is critical to minimizing the risks associated with anterior thoracolumbar spine surgery.

https://thejns.org/doi/abs/10.3171/2020.6.FOCUS20373

KEYWORDS anterior; thoracolumbar; spine; spinal cord; infarct; segmental artery; artery of Adamkiewicz; spinal artery

$\mathrm{T}$ HE spinal segmental arteries are often divided during anterior approaches to the spine. These arteries variably provide supply to the spinal cord; therefore, ligation carries the potential risk of spinal cord ischemia. Given the paucity of data on this topic, we sought to summarize the literature on spinal cord ischemic complications related to anterior thoracolumbar spine surgery through a two-tiered systematic review of this topic, identifying studies that 1) report the incidence of vasculogenic spinal cord injury with anterior thoracolumbar spine pro-

ABBREVIATIONS AKA = artery of Adamkiewicz; $A S A=$ anterior spinal artery; $I O N M=$ intraoperative neuromonitoring; $M E P=$ motor evoked potential; $P S A=$ posterior spinal artery; SSEP = somatosensory evoked potential.

SUBMITTED May 1, 2020. ACCEPTED June 16, 2020.

INCLUDE WHEN CITING DOI: 10.3171/2020.6.FOCUS20373. 
cedures and 2) evaluate operative considerations to prevent such injuries. In addition, we reviewed the key vascular anatomy of the thoracolumbar spine.

\section{Methods}

We performed a systematic review in accordance with the PRISMA statement. ${ }^{1}$ We searched PubMed MEDLINE, Scopus, and Embase databases for terms related to anterior thoracolumbar surgery and vascular injury. The following 5 searches were performed: 1) (("anterior" AND ("thoracolumbar" OR "thoraco-lumbar" OR "thoracic lumbar" OR "thoracic-lumbar" OR "lumbothoracic" OR "lumbo-thoracic" OR "lumbarthoracic" OR "lumbarthoracic")) AND ("spine" OR "spinal” OR "spine surgery" OR "spinal surgery") AND ("vascular" OR "vessel" OR "vessels" OR "artery" OR "arteries" OR "arterial” OR "vein" OR "veins" OR "venous" OR "stroke" OR "infarct" OR "infarction" OR "paraplegia" OR "paraplegic" OR "hemiplegia" OR "hemiplegic")); 2) (("segmental artery ligation" OR "segmental vessel ligation") AND "anterior" AND ("thoracic" OR "thoracolumbar" OR "lumbar") AND ("spine" OR "spinal" OR "spinal surgery" OR "spine surgery")); 3) ("neurologic" AND "vascular" AND ("segmental" OR "adamkiewicz") AND "anterior" AND ("spine" OR "spinal” OR "spine surgery" OR "spinal surgery")); 4) (("anterior spinal fusion" OR ("anterior" AND "spine" AND "fusion")) AND "spinal artery syndrome"); and 5) ("anterior spinal artery syndrome" AND ("thoracolumbar" OR "thoracic" OR "lumbar") AND "anterior surgery" AND "spine"). Databases were searched from inception with no initial restrictions on language or article type. The protocol for this systematic review was not registered.

Articles meeting the following criteria were included: published or translated into the English language, abstract and full-text manuscript available, anterior thoracolumbar approach, and emphasis on neurovascular complications and management of segmental arteries. Additional articles were then identified through a review of the cited references in the included studies.

Study characteristics (design, participants, surgical treatments, and outcomes) were recorded. For reports with patient-level data, we collected patient demographics (age and sex), spinal pathology, presence of kyphosis, operative procedures, segmental vessels ligated, use of intraoperative neuromonitoring (IONM), intra- or postoperative hypotensive events, and outcomes.

\section{Results}

The initial search of PubMed, Scopus, and Embase returned 1200 articles, 16 of which ultimately met the inclusion criteria (Fig. 1). No randomized clinical trials or nonrandomized controlled trials were identified. Study designs included prospective ${ }^{2,3}$ and retrospective ${ }^{4-13}$ cohort studies and case reports. ${ }^{14-17}$ Summaries of the included studies are shown in Tables 1 and 2.

Four retrospective single-center series reported the incidence of neurovascular complications after anterior thoracolumbar spinal surgery.,6-8 Two of these studies were from the same institution and included overlapping time periods and patient populations. ${ }^{4,6}$ One study included only adults, ${ }^{6}$ one included only pediatric patients, ${ }^{7}$ and two included both adult and pediatric patients. ${ }^{4,8}$ The incidence of neurovascular spinal cord complications in these series ranged from $0 \%$ to $0.75 \%$. Among the combined 879 pediatric patients ${ }^{7,8}$ and 929 adult patients, ${ }^{6,8}$ the incidences of neurovascular spinal cord complications were $0.11 \%$ and $0.22 \%$, respectively. Among the 2236 patients in the combined adult and pediatric cohorts, ${ }^{4,8}$ the incidence of neurovascular spinal complications was $0.18 \%$.

Eight studies provided patient-level data for 13 cases of presumed spinal cord infarction due to anterior thoracolumbar surgery (Table 3 ). The mean age of this population was 25 years (range 2-85 years). Nearly all were treated for spinal deformity. Ten $(77 \%)$ were treated with combined anterior and posterior procedures, and IONM was employed in all but 1 case. Changes in IONM occurred in 7 cases (54\%), and only 3 patients $(23 \%)$ had attained a normal functional status at follow-up.

Four studies analyzed specific protocols related to anterior thoracolumbar spinal surgery with respect to ligation of segmental arteries..$^{2,3,5,13}$ Apel et al. ${ }^{2}$ described a protocol for performing temporary occlusion of segmental arteries for 5-15 minutes with concomitant somatosensory evoked potential (SSEP) monitoring, sparing the artery if $>50 \%$ SSEP amplitude reductions were sustained during the temporary occlusion time. Among 44 patients studied with this protocol, SSEP changes were detected in 7 (16\%). All SSEP changes occurred within 5 minutes of temporary occlusion of the segmental arteries, involved complete loss of signal, and returned to baseline after releasing the temporary occlusion. There were no reported neurovascular spinal complications in this study. Similarly, Wu et al. ${ }^{3}$ reported an overall increase in signal latency and decrease in signal amplitude within 7 minutes of temporary occlusion but found that all changes returned to baseline after 17 minutes. All patients underwent ligation of the tested segmental arteries without any postoperative neurovascular spinal complications. Leung et al. ${ }^{13}$ found that patients with certain MRI findings (i.e., syringomyelia and dysraphism) were more likely to have preoperative SSEP abnormalities as well as intraoperative SSEP changes. Additionally, postoperative motor deficits were more common in the high-risk (14.8\%) versus the low-risk $(0.1 \%)$ group, although all postoperative deficits resolved at follow-up. These authors described using temporary occlusion of the segmental arteries in all high-risk patients to assess the safety of ligation, but they did not report on how often surgical plans were adjusted based on these results. Mirovsky et al. ${ }^{5}$ described a concerted effort to preserve segmental arteries during anterior thoracolumbar instrumentation procedures. They were able to achieve this in 7 of 29 patients $(24 \%)$ but noted that segmental artery ligation was required with the use of large-area plates (that required two screws per vertebral body) and threaded cages.

We also identified four studies evaluating the utility of preoperative spinal angiography to delineate the spinal vasculature and inform operative decision-making (Table 4). ${ }^{9-12}$ Each of these studies used catheter-based angiography. Successful identification of the artery of Adamkie- 


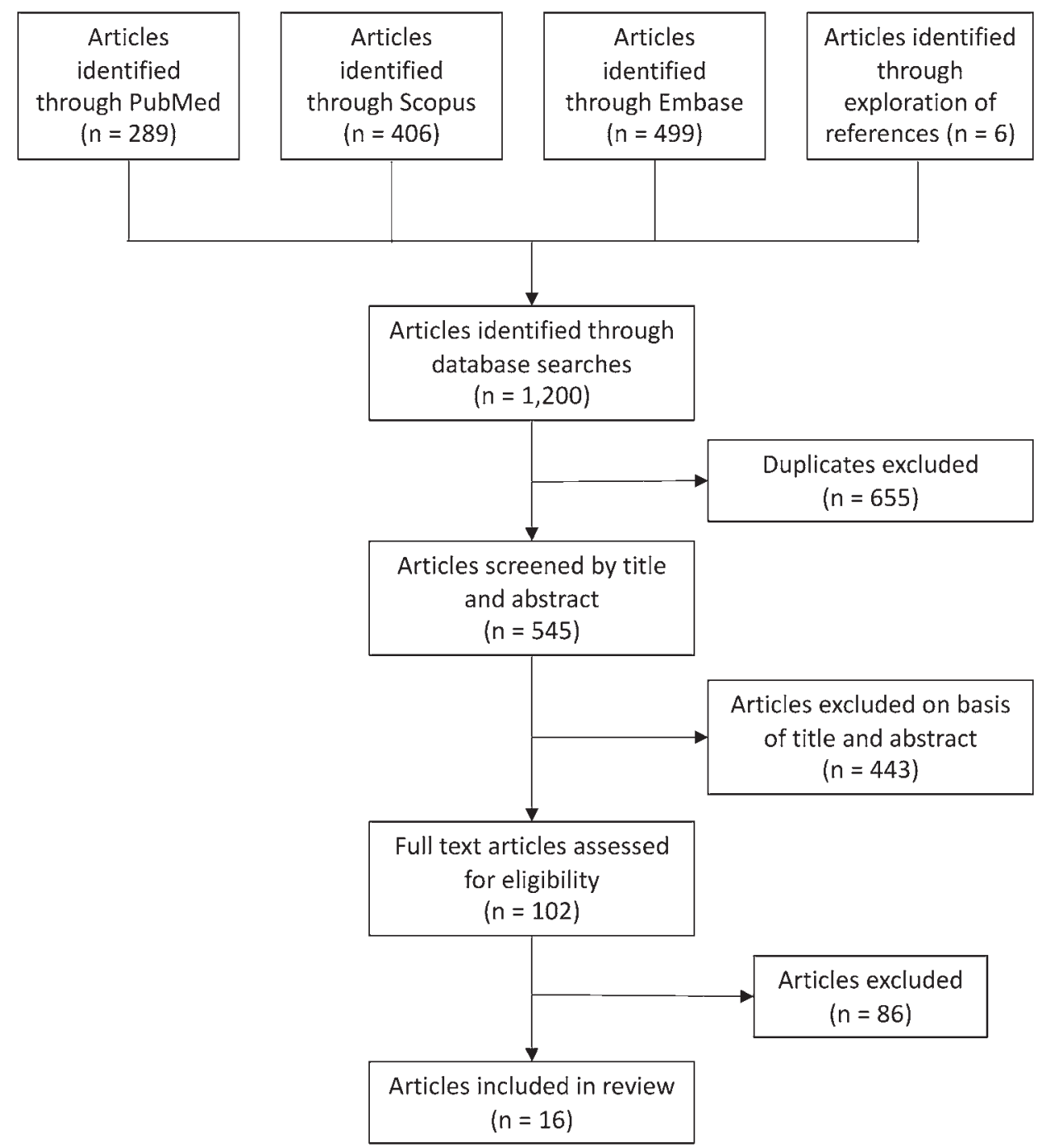

FIG. 1. PRISMA flowchart. Out of the 1200 articles screened in our systematic review, we identified 16 that met the inclusion criteria.

wicz (AKA) was dependent on the catheterization strategy. This artery was identified in $71 \%-96 \%$ of patients in the two studies in which extensive angiography was performed. ${ }^{11,12}$ In addition, although Bassett et al. ${ }^{9}$ did not specify the AKA, they imaged the entire length of the anterior spinal artery (ASA) to identify all radiculomedullary inputs. Champlin et al., ${ }^{10}$ however, only catheterized two levels above and two levels below the planned site of surgery and subsequently identified the AKA in $36 \%$ of patients. In the three studies that specifically identified the AKA, its location at the surgical site resulted in a high likelihood of altered surgical plans $(68 \%-100 \%)$, corresponding to an alteration of surgical plans in 13\%-38\% of all patients undergoing spinal angiography. Such alterations included changing the side of the surgical approach, changing to a posterior approach, or sparing segmental arteries. Bassett et al. ${ }^{9}$ identified 9 segmental arteries with radiculomedullary input at the surgical site and found no SSEP changes with occlusion of these arteries. Overall, there were no instances of spinal cord ischemia in cases in which the surgical plan was not altered despite the presence of the AKA at the surgical site.

\section{Discussion}

Ligation of segmental arteries is a common practice during anterior thoracolumbar spine procedures to facilitate exposure of the anterolateral spinal column. Given the potential for a segmental artery to directly supply the spinal cord, this maneuver poses a risk of spinal cord infarction. In our systematic review, we identified four large cohorts that evaluated this particular complication in the setting of anterior thoracolumbar spine surgery.,6-8 Although a meta-analysis was not appropriate because of variations and overlap in the patient populations, we found that the incidence of this complication is very low, ranging from $0 \%$ to $0.75 \%$ ( $0.11 \%$ for children, $0.22 \%$ for adults, and $0.18 \%$ for studies combining children and adults). Despite 
TABLE 1. Studies reporting neurovascular spinal cord injury

\begin{tabular}{|c|c|c|c|c|}
\hline $\begin{array}{l}\text { Authors } \\
\& \text { Year }\end{array}$ & $\begin{array}{l}\text { Study Design \& } \\
\text { Quality Grade* }\end{array}$ & $\begin{array}{l}\text { Level of } \\
\text { Evidence† }\end{array}$ & Results & Key Conclusions \\
\hline $\begin{array}{l}\text { Ginsburg et } \\
\text { al., } 1985^{16}\end{array}$ & $\begin{array}{l}\text { Case report, } \\
\text { low }\end{array}$ & IV & $\begin{array}{l}\text { Patient had postop paraplegia after } 2 n d \text { stage of } \\
\text { 2-stage ant release \& then fusion despite clearly } \\
\text { identifiable SSEPs }\end{array}$ & $\begin{array}{l}\text { SSEP monitoring can yield false negatives in pa- } \\
\text { tients who sustain neurological injury }\end{array}$ \\
\hline $\begin{array}{l}\text { Ben-David } \\
\text { et al., } 1987^{14}\end{array}$ & $\begin{array}{l}\text { Case report, } \\
\text { low }\end{array}$ & IV & Patient had paraplegia w/o changes in SSEPs & $\begin{array}{l}\text { Intraop SSEPs may not adequately reflect intraop or } \\
\text { postop neurological injury; SSEPs should be used } \\
\text { in combination w/ wake-up test }\end{array}$ \\
\hline $\begin{array}{l}\text { Apel et al., } \\
1991^{2} \ddagger\end{array}$ & $\begin{array}{l}\text { Case report, } \\
\text { low }\end{array}$ & IV & $\begin{array}{l}3 \text { cases of permanent paraplegia after ant spine } \\
\text { surgery }\end{array}$ & $\begin{array}{l}\text { Recommend temporary segmental arterial occlusion } \\
\text { w/ SSEP monitoring to avoid ischemic neurologi- } \\
\text { cal injury }\end{array}$ \\
\hline $\begin{array}{l}\text { Winter et } \\
\text { al., } 1996^{8}\end{array}$ & $\begin{array}{l}\text { Retrospective, } \\
\text { moderate }\end{array}$ & IV & No cases of paralysis after ant approach for T1-L3 & $\begin{array}{l}\text { No risk for neurovascular complications after seg- } \\
\text { mental vessel ligation if unilat, done on convexity } \\
\text { of scoliosis, ligated at mid VB level, \& hypotensive } \\
\text { anesthesia avoided; soft clamping w/ SSEP moni- } \\
\text { toring does not appear justified }\end{array}$ \\
\hline $\begin{array}{l}\text { Bridwell et } \\
\text { al., } 1998^{4}\end{array}$ & $\begin{array}{l}\text { Retrospective, } \\
\text { moderate }\end{array}$ & IV & $\begin{array}{l}4 \text { of } 1090 \text { patients had loss of motor function in LEs } \\
\text { after surgery; } 3 \text { of these patients had deficits of } \\
\text { vascular etiology \& } 1 \text { had deficits of combined } \\
\text { vascular \& mechanical etiology; all } 4 \text { patients } \\
\text { had ant \& pst surgery w/ harvesting of unilat } \\
\text { convex segmental vessels, component of hyper- } \\
\text { kyphosis, \& intraop controlled hypertension }\end{array}$ & $\begin{array}{l}\text { Combined ant \& pst surgery \& hyperkyphosis are } \\
\text { risk factors for neurological deficits after ant spine } \\
\text { surgery }\end{array}$ \\
\hline $\begin{array}{l}\text { Klemme et } \\
\text { al., } 199917\end{array}$ & $\begin{array}{l}\text { Case report, } \\
\text { low }\end{array}$ & IV & $\begin{array}{l}\text { Patient had ischemic myelopathy \& paraplegia } \\
\text { after unilat segmental vessel ligation during ant } \\
\text { scoliosis surgery }\end{array}$ & $\begin{array}{l}\text { Ischemic myelopathy can occur after unilat segmen- } \\
\text { tal vessel ligation in patients w/ greater risk of } \\
\text { cord ischemia }\end{array}$ \\
\hline $\begin{array}{l}\text { Doita et al., } \\
2002^{15}\end{array}$ & $\begin{array}{l}\text { Case report, } \\
\text { low }\end{array}$ & IV & $\begin{array}{l}\text { Patient had paraplegia \& sphincter incontinence } \\
\text { after combined ant \& pst surgery while intraop } \\
\text { SSEPs only showed transient deterioration }\end{array}$ & $\begin{array}{l}\text { SSEP monitoring may not reliably predict overall } \\
\text { neurological outcome involving blood supply of } \\
\text { lower thoracic regions }\end{array}$ \\
\hline $\begin{array}{l}\text { Orchowski } \\
\text { et al., } 2005^{6}\end{array}$ & $\begin{array}{l}\text { Retrospective, } \\
\text { moderate }\end{array}$ & IV & $\begin{array}{l}2 \text { of } 246 \text { patients lost motor function in LEs after } \\
\text { ant thoracolumbar spine surgery; both patients } \\
\text { had staged procedures: PSF then ASF; } 1 \text { had } \\
\text { deficit immediately after surgery \& } 1 \text { had deficit } \\
24 \text { hrs after surgery }\end{array}$ & $\begin{array}{l}\text { Neurological deficit after ant exposure of thoracolum- } \\
\text { bar spine occurred in } 0.75 \% \text { of patients from unilat } \\
\text { It-sided ligation of T10-12 segmental vessels; } \\
\text { risks include prior kyphosis correction, revision } \\
\text { surgery, It-sided approach, \& pst-ant procedures }\end{array}$ \\
\hline $\begin{array}{l}\text { Tsirikos et } \\
\text { al., } 2008^{7}\end{array}$ & $\begin{array}{l}\text { Retrospective, } \\
\text { moderate }\end{array}$ & & $\begin{array}{l}1 \text { of } 346 \text { patients had flaccid paralysis of rt leg \& } \\
127^{\circ} \text { congenital thoracic scoliosis; complication } \\
\text { appeared after ant portion of planned staged ant } \\
\text { then pst surgery }\end{array}$ & $\begin{array}{l}\text { Unilat segmental vessel ligation carries no risk } \\
\text { of neurological damage to spinal cord unless } \\
\text { performed in patients w/ complex congenital } \\
\text { thoracic spinal deformities occurring \& associated } \\
\text { w/ intraspinal anomalies at same level, where } \\
\text { vascular supply to cord may be abnormal }\end{array}$ \\
\hline
\end{tabular}

ant = anterior; $\mathrm{ASF}=$ anterior spinal fusion; $\mathrm{LE}=$ lower extremity; $\mathrm{PSF}=$ posterior spinal fusion; $p s t$ = posterior; $\mathrm{VB}=$ vertebral body.

* The Cochrane ROBINS-I tool was used to qualitatively assess the risk of bias of each included study. See Sterne JA, Hernán MA, Reeves BC, et al. ROBINS-I: a tool for assessing risk of bias in non-randomised studies of interventions. BMJ. 2016;355:i4919.

† Based on Levels of Evidence for Primary Research Question as Adopted by the North American Spine Society January 2005.

$\ddagger$ This study separately presented case reports of spinal vascular injury and a subsequent retrospective series of anterior thoracolumbar surgery patients (see Table 2).

this low incidence, the functional consequences of a spinal cord infarction are devastating, so it is important that the spine surgeon understands the relevant vascular anatomy and potential risk factors.

\section{Thoracolumbar Spinal Vascular Anatomy}

The vascular anatomy of the thoracolumbar region (Fig. 2) follows a simple metameric pattern. Paired segmental arteries arise from each vertebral level of the aorta beginning around T5-6 down to the mid lumbar region, where they may arise from a common trunk. Each segmental artery supplies a corresponding metamer of soft and bony tissue, including its respective hemivertebra, rib, musculature, dura mater, and spinal nerve. ${ }^{18}$ The segmental arteries course posteriorly from their origin at the aorta along the midportion of the vertebral body ${ }_{10}{ }^{19}$ giving rise to multiple somatic and osseous branches that supply the hemivertebra and adjacent soft tissue. ${ }^{18,20}$ At the level of the neural foramen, the segmental artery divides into 
TABLE 2. Studies reporting on operative considerations to prevent neurovascular spinal cord injury

\begin{tabular}{|c|c|c|c|c|}
\hline $\begin{array}{l}\text { Authors } \\
\text { \& Year }\end{array}$ & $\begin{array}{l}\text { Study Design \& } \\
\text { Quality Grade* }\end{array}$ & $\begin{array}{c}\text { Level of } \\
\text { Evidence }\end{array}$ & Results & Key Conclusions \\
\hline $\begin{array}{l}\text { Apel et al., } \\
1991^{2} \ddagger\end{array}$ & $\begin{array}{l}\text { Retrospective, } \\
\text { moderate }\end{array}$ & IV & $\begin{array}{l}3 \text { cases of permanent paraplegia after ant spine } \\
\text { surgery; } 7 \text { cases complete loss of SSEPs, } \\
\text { reversible by release of vascular clips }\end{array}$ & $\begin{array}{l}\text { Recommend temporary segmental arterial oc- } \\
\text { clusion w/ SSEP monitoring to avoid ischemic } \\
\text { neurological injury }\end{array}$ \\
\hline $\begin{array}{l}\text { Champlin et } \\
\text { al., } 1994^{10}\end{array}$ & $\begin{array}{l}\text { Retrospective, } \\
\text { moderate }\end{array}$ & IV & $\begin{array}{l}\text { Arterial supply to spinal cord in region of planned } \\
\text { surgery in } 77 \% \text { of patients; surgical approach } \\
\text { modified to pst approach or to different side for } \\
\text { lat extracavitary approach }\end{array}$ & $\begin{array}{l}\text { Spinal angiography is safe preop exam for ant tho- } \\
\text { racolumbar spine surgery; spinal angiography } \\
\text { useful when lat extracavitary approach to spinal } \\
\text { cord decompression \& fusion planned }\end{array}$ \\
\hline $\begin{array}{l}\text { Bassett et al., } \\
1996^{9}\end{array}$ & $\begin{array}{l}\text { Retrospective, } \\
\text { moderate }\end{array}$ & IV & $\begin{array}{l}\text { Temporary occlusion of } 9 \text { segmental arteries in } \\
\text { surgical field did not result in SSEP changes in } \\
15 \text { patients }\end{array}$ & $\begin{array}{l}\text { Lack of SSEP changes after temporary occlu- } \\
\text { sion of segmental arteries indicates sufficient } \\
\text { paramedullary collateral circulation }\end{array}$ \\
\hline $\begin{array}{l}\text { Leung et al., } \\
2005^{13}\end{array}$ & $\begin{array}{l}\text { Retrospective, } \\
\text { moderate }\end{array}$ & IV & $\begin{array}{l}5 \text { patients at increased risk of cord ischemia \& } 1 \\
\text { patient w/ standard risk w/ postop neurologi- } \\
\text { cal deficit had intraop changes in SSEPs after } \\
\text { segmental artery ligation }\end{array}$ & $\begin{array}{l}\text { Patient w/ risk of spinal cord ischemia should un- } \\
\text { dergo spinal cord monitoring during ant spinal } \\
\text { deformity surgery; soft clamping of segmental } \\
\text { vessels w/ cord monitoring can prevent postop } \\
\text { neurological deficits }\end{array}$ \\
\hline $\begin{array}{l}\text { Mirovsky et } \\
\text { al., } 2007^{5}\end{array}$ & $\begin{array}{l}\text { Retrospective, } \\
\text { moderate }\end{array}$ & IV & $\begin{array}{l}\text { In } 7 \text { patients w/ segmental vessels preserved, } 1 \\
\text { screw used per VB; in } 22 \text { patients w/ segmental } \\
\text { vessels not preserved, } 2 \text { screws used per VB }\end{array}$ & $\begin{array}{l}\text { Segmental vessels can be preserved using } 1 \\
\text { screw per VB; ligation of segmental vessels } \\
\text { necessary when } 2 \text { screws used per VB; enough } \\
\text { room above \& below segmental vessels for } \\
\text { insertion of large screw, even w/ a staple }\end{array}$ \\
\hline $\begin{array}{l}\text { Charles et al., } \\
2011^{11}\end{array}$ & $\begin{array}{l}\text { Retrospective, } \\
\text { moderate }\end{array}$ & IV & $\begin{array}{l}\text { AKA always located btwn T8 \& L3, including T9 or } \\
\text { T10 in 50\% of patients; AKA arose from It side } \\
\text { in } 75 \% \text { of patients; concordance btwn topog- } \\
\text { raphy of AKA \& planned surgical approach in } \\
15 \% \text { of patients; side changings \& modifications } \\
\text { of surgical technique used to avoid AKA }\end{array}$ & $\begin{array}{l}\text { Spinal angiography allows safe determination of } \\
\text { AKA; surgeons should use contralat approach } \\
\text { or avoid vessel ligation if AKA \& planned surgi- } \\
\text { cal approach concord }\end{array}$ \\
\hline
\end{tabular}

* The Cochrane ROBINS-I tool was used to qualitatively assess the risk of bias of each included study. See Sterne JA, Hernán MA, Reeves BC, et al. ROBINS-I: a tool for assessing risk of bias in non-randomised studies of interventions. BMJ. 2016;355:i4919.

† Based on Levels of Evidence for Primary Research Question as Adopted by the North American Spine Society January 2005.

$\ddagger$ This study separately presented case reports of spinal vascular injury and a subsequent retrospective series of anterior thoracolumbar surgery patients (see Table 1 ).

two main branches: 1) the intercostal artery that courses laterally along the underside of the respective rib (or the muscular artery in the lumbar spine that courses along the posterior abdominal wall) and 2) the dorsal spinal artery. This latter artery then divides into a radicular artery and a dorsal branch, which courses posteriorly to supply the hemilamina and adjacent posterior paraspinal musculature and soft tissues. The radicular artery courses along the nerve root sleeve to supply the adjacent dura and is typically present at every level..$^{18}$

The arterial supply to the spinal cord arises from three longitudinal arteries that run the length of the spinal cord: the midline ASA that sits within the median sulcus anteriorly and the paired posterior spinal arteries (PSAs) that run along the posterolateral aspects of the spinal cord. ${ }^{21}$ The ASA is largely continuous, while the PSAs may have a discontinuous course. The ASA gives rise to sulcal arteries that dive deep into the median sulcus and then branch outward to largely supply the gray matter within the anterior and central portions of the spinal cord in a centrifugal pattern. Conversely, the PSAs give rise to a pial network along the periphery of the spinal cord that dives inward to supply white matter in a centripetal pattern.

Supply to the ASA and PSAs comes from prominent 


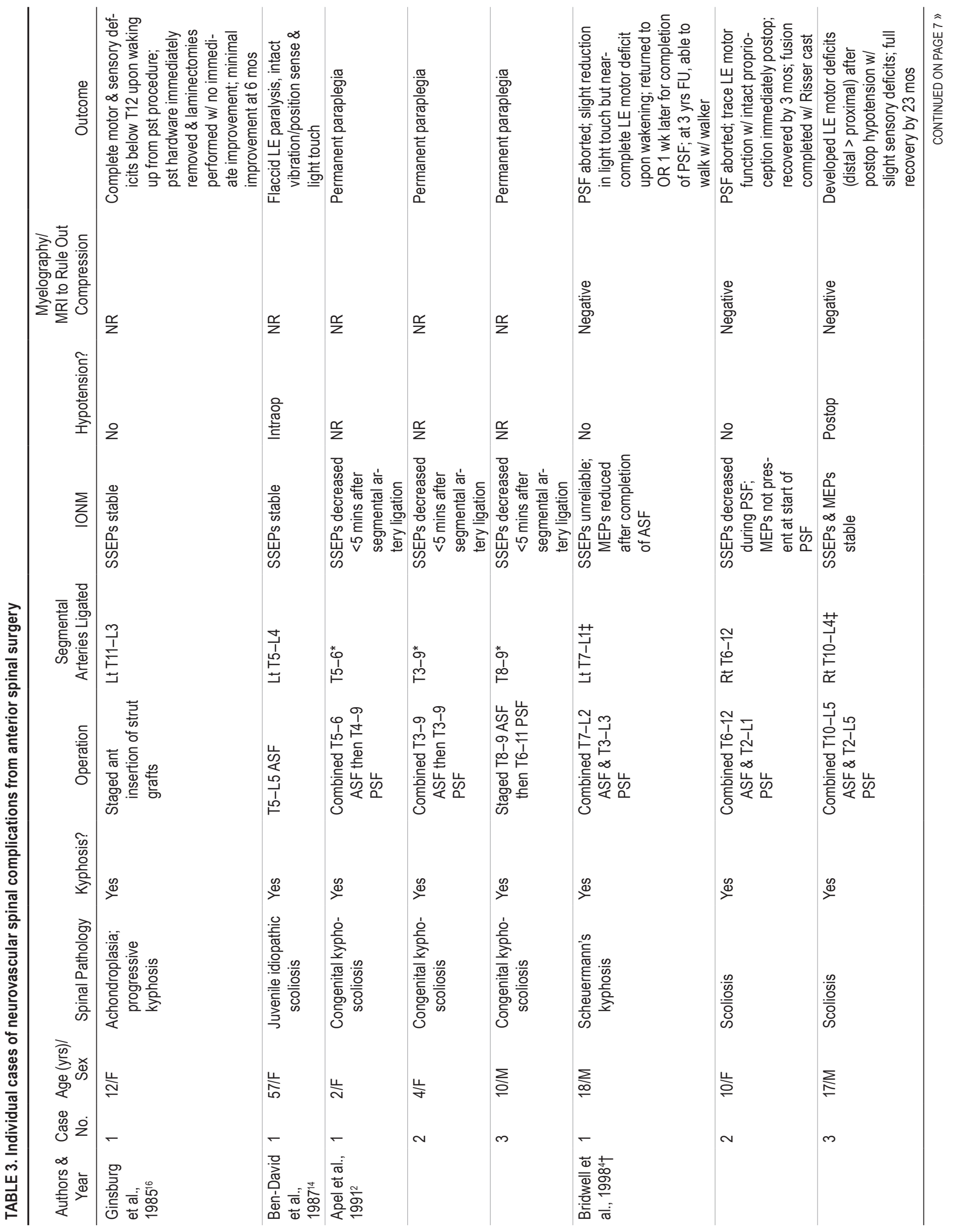




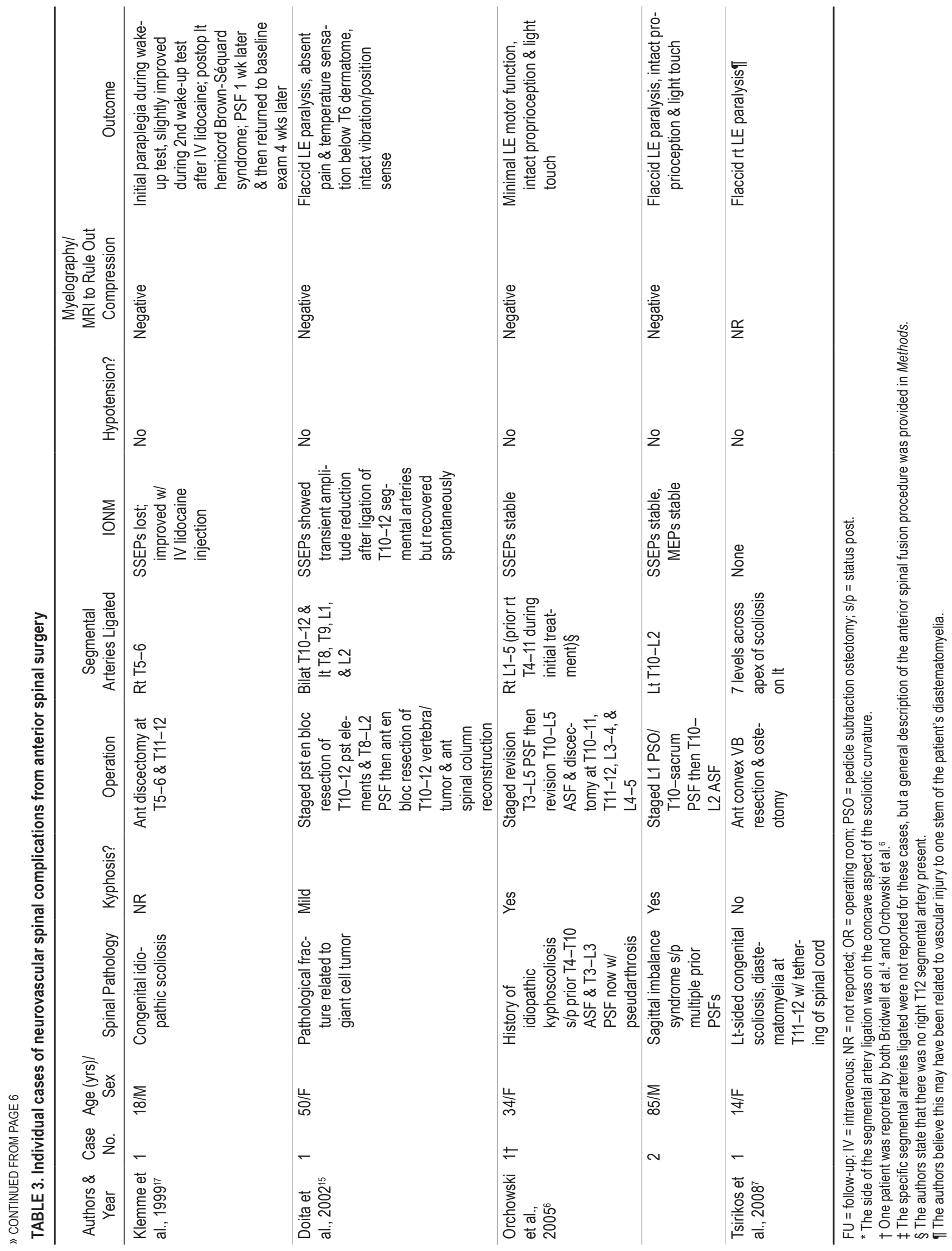


TABLE 4. Studies using preoperative spinal angiography for anterior thoracolumbar spine surgery

\begin{tabular}{cccccc}
\hline $\begin{array}{c}\text { Authors } \\
\& \text { Year }\end{array}$ & $\begin{array}{c}\text { No. of } \\
\text { Patients }\end{array}$ & $\begin{array}{c}\text { AKA } \\
\text { Identified }\end{array}$ & $\begin{array}{c}\text { AKA at } \\
\text { Surgical Site* }\end{array}$ & \% Patients w/ AKA at Surgical Site & \% All Patients Tested \\
\hline Champlin et al., 199410 & 61 & $22(36 \%)$ & $17(77 \%) \dagger$ & $17(100 \%)$ & $28 \%$ \\
\hline Bassett et al., 1996 & 16 & $16(100 \%) \dagger$ & $9(56 \%)$ & 0 & 0 \\
\hline Fanous et al., 201512 & 34 & $24(71 \%)$ & $19(79 \%)$ & $13(68 \%)$ & $38 \%$ \\
\hline Charles et al., 201111 & 100 & $96(96 \%)$ & $15(16 \%)$ & $13(87 \%)$ & $13 \%$ \\
\hline
\end{tabular}

* Listed as the percentage of the cases in which the AKA was identified.

$\dagger$ This study did not specify the AKA but identified thoracolumbar radiculomedullary branches in each patient.

radicular branches called the "radiculomedullary arteries" and "radiculopial arteries," respectively. ${ }^{18,21}$ These arteries course along the nerve root and therefore have a typical superomedial course on anteroposterior spinal angiography with a hairpin turn where they connect to the ASA or PSA, respectively (Figs. 3 and 4). These branches arise from multiple arterial inputs throughout the spinal column. In the cervical and upper thoracic spine, radiculomedullary and radiculopial branches can arise from the vertebral ar- teries, the ascending and deep cervical arteries, and the supreme intercostal arteries. In the mid-lower thoracic spine and upper lumbar spine, these arteries arise from the segmental arteries. Radiculomedullary and radiculopial arteries are not present at every level, and their number and location vary. In the thoracolumbar spine, there are typically $2-3$ radiculomedullary feeders and $8-16$ radiculopial feeders. ${ }^{21}$ The number of radiculopial feeders is often inversely correlated with caliber. ${ }^{21}$ The eponymous AKA,
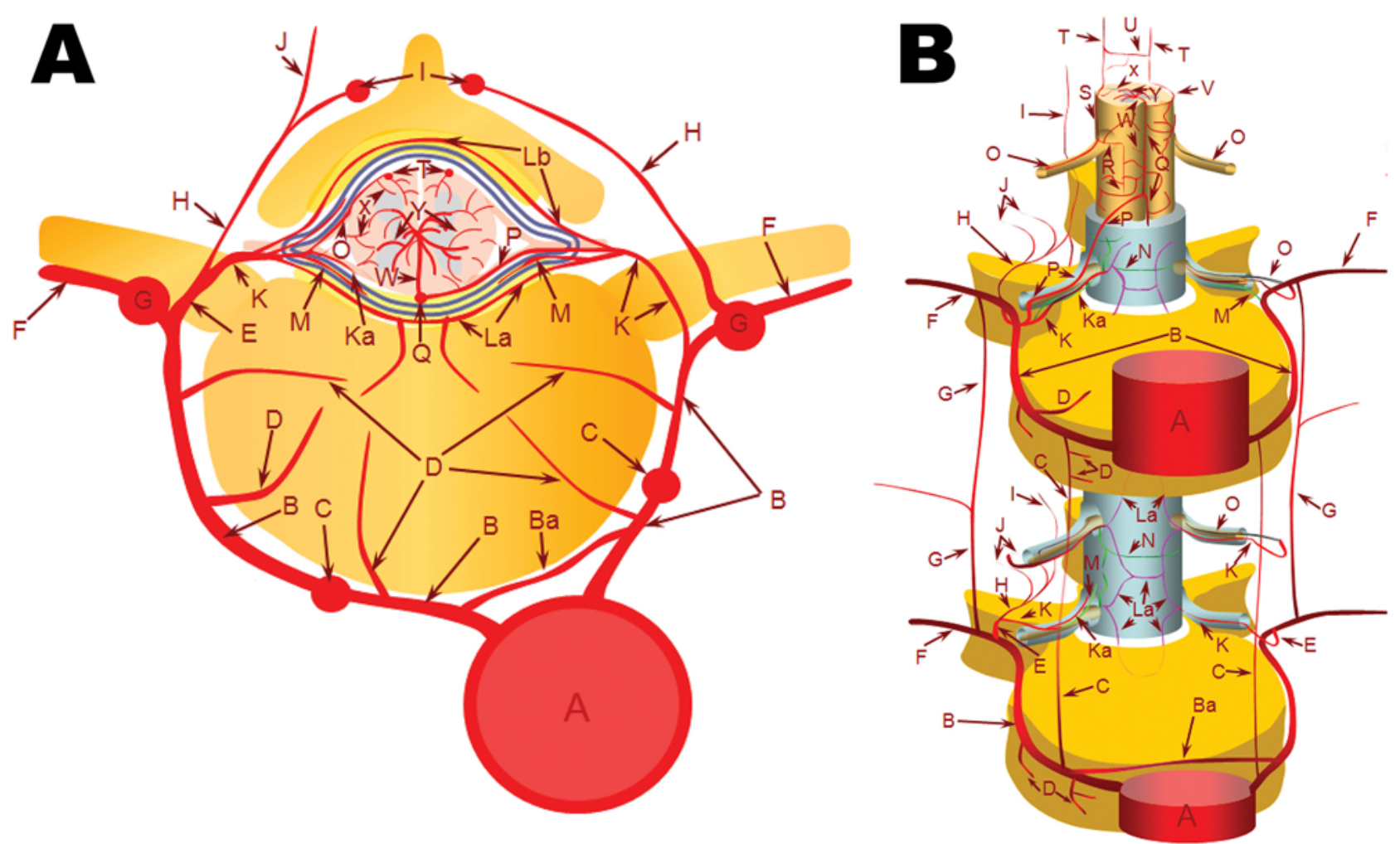

FIG. 2. Spinal vascular anatomy. $A$ xial $(\mathbf{A})$ and oblique $(B)$ views of the spine detailing spinal vascular anatomy. $A=a$ aorta; $B=$ segmental arteries; $\mathrm{Ba}=$ intersegmental anastomotic artery; $\mathrm{C}=$ prevertebral anastomotic network; $\mathrm{D}=$ direct vertebral body feeding arteries; $\mathrm{E}=$ dorsal spinal artery; $\mathrm{F}=$ intercostal/muscular artery; $\mathrm{G}=$ pretransverse anastomotic network; $\mathrm{H}=$ dorsal division of the dorsal spinal artery; I = posttransverse anastomotic network; $\mathrm{J}=$ muscular branches of the posttransverse anastomotic network; $K=$ ventral division of the dorsal spinal artery; $K a=$ radicular artery; $L a=$ ventral epidural arcade; $L b=$ dorsal epidural arcade; $\mathrm{M}=$ nerve root sleeve dural branch of the ventral division dorsal spinal artery; $\mathrm{N}=$ dural branch of the ventral division dorsal spinal artery; $O=$ radiculopial artery; $P=$ radiculomedullary artery; $Q=A S A ; R=$ mesh-like pial arterial network; $S$ and $T=$ PSAs; $U$ and $V=$ pial arterial network anastomoses between anterior and posterior spinal arterial systems; $W=$ sulco-commissural artery; $X=$ rami perforantes of the peripheral (centripetal) system; $Y=$ central (centrifugal) system of sulcal arteries, originating from pial network of the cord. Used with permission from neuroangio.org. 

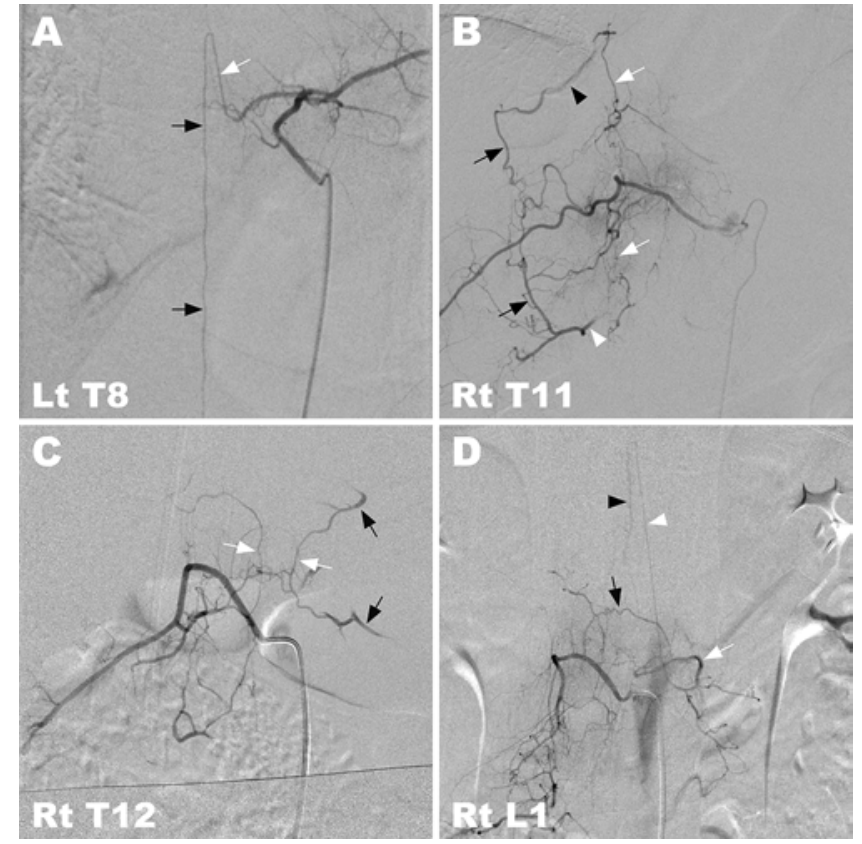

FIG. 3. Key spinal vascular anatomy and anastomotic networks. A: Left T8 selective injection showing a prominent radiculomedullary artery (AKA, white arrow) supplying the midline ASA (black arrows). B: Right T11 selective injection showing paraspinal (white arrows) and chest wall (black arrows) longitudinal anastomoses resulting in opacification of the adjacent T10 (black arrowhead) and T12 (white arrowhead) segmental/ intercostal arteries. C: Right T12 selective injection demonstrating opacification of the retrocorporeal anastomotic plexus (white arrows) with filling of contralateral segmental arteries (black arrows). D: Right L1 selective injection showing collateral opacification of the contralateral segmental artery (white arrow) via precorporeal anastomotic collaterals (black arrow), which gives rise to a prominent radiculomedullary artery (AKA, white arrowhead) supplying the ASA (black arrowhead). The precorporeal anastomotic network is distinguished from the retrocorporeal by its more proximal origin from the segmental artery.

or artery of the lumbar enlargement, is a dominant radiculomedullary artery typically found in the thoracolumbar region between $\mathrm{T} 8$ and $\mathrm{L} 2$. It arises from the left in $80 \%$ of cases. ${ }^{18}$ In the absence of an AKA, multiple radiculomedullary arteries may be seen in the thoracolumbar region..$^{18}$

The spinal arterial system is notable for rich collateralization between adjacent vertebral levels and from side to side (Figs. 2-4). Multiple longitudinal networks connect the segmental arteries and their branches between adjacent vertebral levels. The main network is the paravertebral or pretransverse network located between the rib and transverse process. This connects adjacent dorsal spinal arteries and is often seen on spinal angiography with filling of segmental arteries above and below the selected segmental artery. Other potential longitudinal anastomoses are located along the anterolateral aspect of the vertebral body, the spinous processes, and even further lateral connecting adjacent intercostal arteries. In addition, anastomotic networks exist along both the anterior (precorporeal) and posterior (retrocorporeal) aspects of the vertebral bodies (Figs. 2 and 3), providing collaterals between adjacent vertebral levels as well as the two segmental systems at a giv-
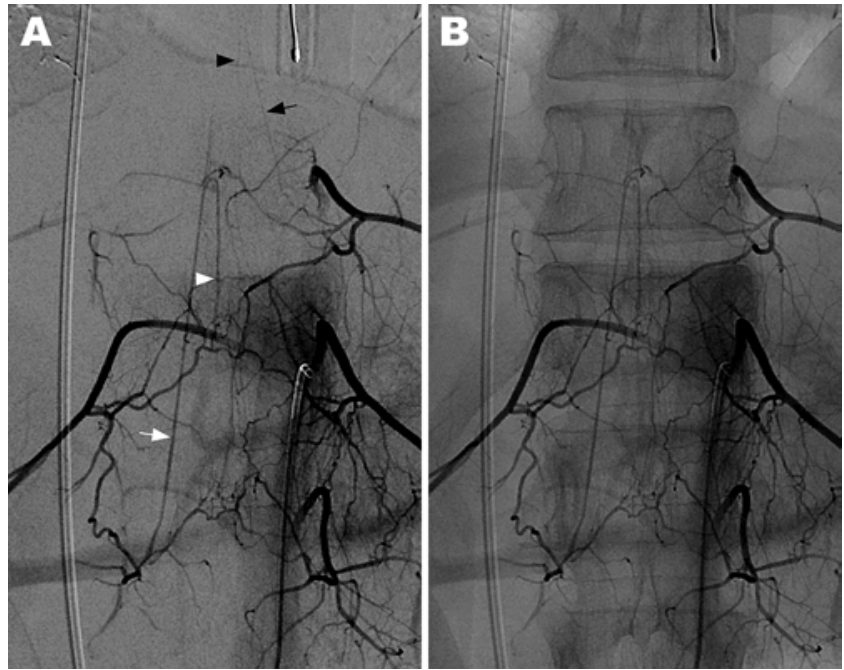

FIG. 4. Multiple anastomotic networks. Subtracted (A) and unsubtracted (B) images from a left T12 selective injection demonstrate opacification of the adjacent left T11 and L1 segmental arteries as well as the right T12 segmental artery via multiple longitudinal and transverse collateral connections. The AKA (white arrow) arises from the right L1 to supply the ASA (white arrowhead). A radiculopial artery (black arrow) arises from the left T11 segmental artery to supply the left PSA (black arrowhead).

en vertebral level. The precorporeal network is identified by its origin from the proximal segmental artery, while the retrocorporeal anastomoses are commonly seen as a diamond-shaped network on spinal angiography. Importantly, the ASA and PSA themselves have collateral potentials via the multiple radiculomedullary and radiculopial arteries that supply them.

Given the vast collateral networks surrounding the vertebral bodies, anterior thoracolumbar approaches can compromise more than just a given segmental artery. Exposure of the lateral spinal column and removal of the rib head can obliterate the precorporeal and pretransverse networks, corpectomy can compromise the retrocorporeal networks, and laminectomy will remove the spinous process networks.

\section{Impact of Segmental Artery Ligation on Spinal Cord Perfusion}

Several preclinical studies have evaluated the consequences of unilateral or bilateral segmental artery ligation on spinal cord perfusion. In a canine model, Fujimaki et al. ${ }^{22}$ and Kato et al. ${ }^{23}$ found that ligation of 5 adjacent bilateral levels resulted in a $56 \%$ reduction in spinal cord blood flow and concomitant IONM changes. The sacrifice of 7 adjacent levels caused a 75\% reduction in spinal cord blood flow and more significant IONM changes. ${ }^{22}$ The canine equivalent of the AKA typically originates from an L5 segmental artery, and similar findings occurred when this level was included in the sacrificed segmental vessels. ${ }^{23}$ The sacrifice of $\leq 3$ adjacent bilateral segmental arteries did not result in clinically significant reductions in spinal cord perfusion. ${ }^{22-24}$ Yuan et al. ${ }^{25}$ performed a similar experiment using fresh human cadavers, finding a 
progressive reduction in the number and density of spinal cord blood vessels with an increasing number of ligated segmental arteries.

\section{Risk Factors Associated With Vasculogenic Spinal Injury}

Several studies have discussed potential risk factors for vasculogenic spinal cord injury during anterior thoracolumbar spine surgery, including the presence of hyperkyphosis ${ }^{4}$ and prior spinal deformity surgery. ${ }^{6}$ Considering a complication in a single patient with a complex spinal dysraphism (including diastematomyelia), Tsirikos et al. ${ }^{7}$ suggested that complex congenital deformities within the thoracic spine may be a risk factor as well. Similarly, Leung et al. ${ }^{13}$ found that patients with intraspinal findings on MRI, including syringomyelia and spinal dysraphism, were more likely to demonstrate IONM changes and more likely to have postoperative neurological deficits after anterior thoracolumbar spine procedures. Surgical risk factors identified from the literature include combined anterior-posterior procedures, ${ }^{4,6}$ a left-sided approach, ${ }^{6}$ ligation of bilateral segmental arteries at a given level, ${ }^{8}$ and ligation of segmental arteries at the concavity (as opposed to convexity) of a scoliotic curve. ${ }^{8}$ The AKA is most likely to arise from a left-sided segmental artery, so left-sided approaches will have a higher likelihood of ligating the segmental artery supplying the AKA. Perioperative hypotension and hypotensive anesthesia have been identified as additional risk factors. ${ }^{8}$ In a setting in which a radiculomedullary or radiculopial artery has lost its direct segmental supply, intra- or postoperative hypotension may compromise collateral supply. Similarly, standard vascular risk factors (i.e., hypertension, hypercholesterolemia, and diabetes) have also been implicated in spinal infarction associated with anterior thoracolumbar surgery since they may also affect the quality of potential collaterals. $^{7}$

\section{Intraoperative Neuromonitoring}

IONM is a common practice in spinal surgery despite a lack of significant data supporting improved outcomes with its use. ${ }^{26}$ The first technique used to assess neurological function during spinal surgery was the Stagnara wake-up test, in which the patient's sedation is sufficiently lightened to allow for a neurological examination. ${ }^{27}$ The majority of cases reporting spinal cord ischemic complications related to anterior thoracolumbar surgery utilized intraoperative SSEPs. SSEPs monitor the posterior columns within the spinal cord, a territory served in large part by the PSAs. Several studies used SSEPs alone as a marker for spinal cord perfusion, and we identified several cases of paraplegia related to anterior thoracolumbar surgery in which intraoperative SSEP signals were lost. ${ }^{2,15,17}$ These latter cases, as well as reports of SSEPs during temporary occlusion of segmental arteries, ${ }^{2,28}$ demonstrated rapid changes in SSEPs upon segmental artery occlusion. The sensitivity of SSEPs for pure ASA ischemia is low, ${ }^{26}$ however, and several case reports described postoperative motor deficits despite stable intraoperative SSEPs. ${ }^{4,6,14,16}$

Motor evoked potentials (MEPs) monitor function of the corticospinal tract and therefore have a higher sensitivity for detecting motor deficits. ${ }^{26}$ MEPs were used in 4 of the cases of postoperative deficits after anterior spinal surgery. In 2 patients, SSEPs and MEPs remained stable. ${ }^{4,6}$ One of these patients had documented intact motor function in the immediate postoperative period but then suffered an episode of hypotension, after which he developed lower-extremity paraplegia. ${ }^{4}$ In another 2 patients, MEPs were found to be reduced after the anterior portion of a combined anterior-posterior procedure. ${ }^{4}$ In each of these cases, a wake-up test was performed during the posterior portion of the operation. When significant motor deficits were detected, the implanted posterior hardware was removed and the cases aborted. We did not find any studies using MEPs during temporary occlusion of segmental arteries.

\section{Preoperative Spinal Angiography}

Preoperative catheter spinal angiography has been employed to locate the AKA and other radiculomedullary and radiculopial branches prior to anterior thoracolumbar surgery. Some authors performed an exhaustive examination of the ASA to identify all of its radiculomedullary inputs, $, 911,12$ while others performed a focused examination including two segmental levels above and below the pathological level, ${ }^{10}$ thereby shortening the procedure and limiting contrast and radiation exposure. Identification of the AKA can also be performed using noninvasive MR or CT spinal angiography with high sensitivities, ${ }^{29}$ although we did not identify any studies investigating the role of these noninvasive modalities in operative decision-making for anterior thoracolumbar surgery. In several instances, identification of the AKA at the surgical site resulted in changes to the planned operative approach. Such modifications are not always possible but can certainly be considered if they allow sparing of the AKA.

\section{Operative Considerations}

Although there are no randomized trials comparing operative techniques with regard to neurovascular complications, several studies proposed safe practices that may help to avoid spinal cord ischemia. Winter et al. ${ }^{8}$ reported that segmental artery ligation should be performed when the segmental artery crosses the midportion of the vertebral body to avoid compromising collateral branches at the level of the foramen. They also suggested that ligation of segmental vessels along the convexity of a scoliotic curve is safer than along the concavity because the convexity vessels tend to be smaller and are therefore less likely to be critical for spinal perfusion. There are few reports of spinal angiography in scoliosis patients, but there is some evidence to suggest that a scoliotic deformity affects the ASA, with decreased flow at the level of the scoliotic apex. ${ }^{30}$ This flow improves after correction of the deformity, suggesting that the collateral potential of the anterior spinal cord itself may be reduced in severe scoliosis.

Mirovsky et al. ${ }^{5}$ described a method to preserve and protect segmental arteries by elevating periosteal flaps on either side of the artery. They were only able to achieve segmental artery preservation in $24 \%$ of cases, however. The main determinant for this was the type of hardware used, with large plates and expandable cages precluding preservation of the segmental arteries. 


\section{Study Limitations}

We acknowledge several limitations to this systematic review. First, the quality of evidence from the studies included in this review is low given the predominance of retrospective cohort studies and case reports without comparison groups. In addition, the overall risk of spinal cord ischemic injury related to ligation of segmental arteries in anterior thoracolumbar surgery is very low. Risk factors and preventative measures must therefore be viewed in light of this low incidence.

\section{Conclusions}

Vasculogenic spinal cord injury during anterior thoracolumbar spine surgery is rare, occurring in well below $1 \%$ of cases, but it can have devastating consequences. Such injury primarily occurs due to ligation of segmental arteries or interruption of associated arterial collateral networks. Several potential risk factors have been identified, including significant kyphosis, prior spinal deformity surgery, the presence of intraspinal abnormalities or dysraphism, combined anterior-posterior procedures, left-sided approaches, operating on the concavity of a scoliotic curve, and intra- or postoperative hypotension. Preoperative angiography may be useful to identify the AKA and inform surgical planning, while IONM with SSEPs and MEPs can be used to test-occlude target segmental arteries or detect any ischemic changes to the spinal cord. Most importantly, a thorough understanding of the relevant spinal vascular anatomy is crucial to maximizing the safety of these procedures. The importance of studying vascular anatomy in relation to the spine, especially in the context of spinal deformity, cannot be overstated. A thorough examination of preoperative imaging to identify the course of major vasculature in relation to the curvature and $3 \mathrm{D}$ deformation may dictate the type of corrective surgical approach and type of implants used. Given the paucity of literature on this subject, future studies into preoperative imaging, intraoperative testing, and surgical decision-making are warranted to help improve the safety of anterior thoracolumbar spine surgery.

\section{References}

1. Moher D, Liberati A, Tetzlaff J, et al. Preferred Reporting Items for Systematic Reviews and Meta-Analyses: the PRISMA statement. PLoS Med. 2009;6(7):e1000097.

2. Apel DM, Marrero G, King J, et al. Avoiding paraplegia during anterior spinal surgery. The role of somatosensory evoked potential monitoring with temporary occlusion of segmental spinal arteries. Spine (Phila Pa 1976). 1991;16(8)(suppl): S365-S370.

3. Wu L, Qiu Y, Ling W, Shen Q. Change pattern of somatosensory-evoked potentials after occlusion of segmental vessels: possible indicator for spinal cord ischemia. Eur Spine J. 2006;15(3):335-340.

4. Bridwell KH, Lenke LG, Baldus C, Blanke K. Major intraoperative neurologic deficits in pediatric and adult spinal deformity patients. Incidence and etiology at one institution. Spine (Phila Pa 1976). 1998;23(3):324-331.

5. Mirovsky Y, Hod-Feins R, Agar G, Anekstein Y. Avoiding neurologic complications following ligation of the segmental vessels during anterior instrumentation of the thoracolumbar spine. Spine (Phila Pa 1976). 2007;32(2):275-280.
6. Orchowski J, Bridwell KH, Lenke LG. Neurological deficit from a purely vascular etiology after unilateral vessel ligation during anterior thoracolumbar fusion of the spine. Spine (Phila Pa 1976). 2005;30(4):406-410.

7. Tsirikos AI, Howitt SP, McMaster MJ. Segmental vessel ligation in patients undergoing surgery for anterior spinal deformity. J Bone Joint Surg Br. 2008;90(4):474-479.

8. Winter RB, Lonstein JE, Denis F, et al. Paraplegia resulting from vessel ligation. Spine (Phila Pa 1976). 1996;21(10): $1232-1234$.

9. Bassett G, Johnson C, Stanley P. Comparison of preoperative selective spinal angiography and somatosensory-evoked potential monitoring with temporary occlusion of segmental vessels during anterior spinal surgery. Spine (Phila Pa 1976). 1996;21(17):1996-2000.

10. Champlin AM, Rael J, Benzel EC, et al. Preoperative spinal angiography for lateral extracavitary approach to thoracic and lumbar spine. AJNR Am J Neuroradiol. 1994;15(1):73-77.

11. Charles YP, Barbe B, Beaujeux R, et al. Relevance of the anatomical location of the Adamkiewicz artery in spine surgery. Surg Radiol Anat. 2011;33(1):3-9.

12. Fanous AA, Lipinski LJ, Krishna C, et al. The impact of preoperative angiographic identification of the artery of Adamkiewicz on surgical decision making in patients undergoing thoracolumbar corpectomy. Spine (Phila Pa 1976). 2015; 40(15):1194-1199.

13. Leung YL, Grevitt M, Henderson L, Smith J. Cord monitoring changes and segmental vessel ligation in the "at risk" cord during anterior spinal deformity surgery. Spine (Phila Pa 1976). 2005;30(16):1870-1874.

14. Ben-David B, Haller G, Taylor P. Anterior spinal fusion complicated by paraplegia. A case report of a false-negative somatosensory-evoked potential. Spine (Phila Pa 1976). 1987;12(6):536-539.

15. Doita M, Marui T, Nishida K, et al. Anterior spinal artery syndrome after total spondylectomy of T10, T11, and T12. Clin Orthop Relat Res. 2002;(405):175-181.

16. Ginsburg HH, Shetter AG, Raudzens PA. Postoperative paraplegia with preserved intraoperative somatosensory evoked potentials. Case report. J Neurosurg. 1985;63(2):296-300.

17. Klemme WR, Burkhalter W, Polly DW Jr, et al. Reversible ischemic myelopathy during scoliosis surgery: a possible role for intravenous lidocaine. J Pediatr Orthop. 1999;19(6): $763-765$.

18. Lasjaunias P, Berenstein A, ter Brugge KG. Surgical Neuroangiography. Vol. 1. 2nd ed. Springer-Verlag GmbH; 2001.

19. Gao L, Wang L, Su B, et al. The vascular supply to the spinal cord and its relationship to anterior spine surgical approaches. Spine J. 2013;13(8):966-973.

20. Alleyne CH Jr, Cawley CM, Shengelaia GG, Barrow DL. Microsurgical anatomy of the artery of Adamkiewicz and its segmental artery. J Neurosurg. 1998;89(5):791-795.

21. Thron AK. Vascular Anatomy of the Spinal Cord. Springer; 1988.

22. Fujimaki Y, Kawahara N, Tomita K, et al. How many ligations of bilateral segmental arteries cause ischemic spinal cord dysfunction? An experimental study using a dog model. Spine (Phila Pa 1976). 2006;31(21):E781-E789.

23. Kato S, Kawahara N, Tomita K, et al. Effects on spinal cord blood flow and neurologic function secondary to interruption of bilateral segmental arteries which supply the artery of Adamkiewicz: an experimental study using a dog model. Spine (Phila Pa 1976). 2008;33(14):1533-1541.

24. Ueda Y, Kawahara N, Tomita K, et al. Influence on spinal cord blood flow and function by interruption of bilateral segmental arteries at up to three levels: experimental study in dogs. Spine (Phila Pa 1976). 2005;30(20):2239-2243.

25. Yuan L, Ni GX, Luk KKD, et al. Effect of segmental artery ligation on the blood supply of the thoracic spinal cord dur- 
ing anterior spinal surgery: a quantitative histomorphological fresh cadaver study. Spine (Phila Pa 1976). 2005;30(5): 483-486.

26. Lall RR, Lall RR, Hauptman JS, et al. Intraoperative neurophysiological monitoring in spine surgery: indications, efficacy, and role of the preoperative checklist. Neurosurg Focus. 2012;33(5):E10.

27. Vauzelle C, Stagnara P, Jouvinroux P. Functional monitoring of spinal cord activity during spinal surgery. Clin Orthop Relat Res. 1973;(93):173-178.

28. Wu T, Xiao L, Liu C, et al. Anatomical study of the lumbar segmental arteries in relation to the oblique lateral interbody fusion approach. World Neurosurg. 2020;138:e778-e786.

29. Yoshioka K, Niinuma H, Ehara S, et al. MR angiography and CT angiography of the artery of Adamkiewicz: state of the art. Radiographics. 2006;26(suppl 1):S63-S73.

30. Hilal SK, Keim HA. Selective spinal angiography in adolescent scoliosis. Radiology. 1972;102(2):349-359.

\section{Disclosures}

Dr. Dahdaleh is a consultant for DePuy.

\section{Author Contributions}

Conception and design: Potts. Acquisition of data: Potts, Shlobin, Raz, Clark, Hoffman. Analysis and interpretation of data: Potts, Shlobin, Shapiro, Dahdaleh. Drafting the article: Potts, Shlobin. Critically revising the article: Potts, Shapiro, Shaibani, Hurley, Ansari, Jahromi, Dahdaleh. Reviewed submitted version of manuscript: Potts. Approved the final version of the manuscript on behalf of all authors: Potts. Study supervision: Potts.

\section{Correspondence}

Matthew B. Potts: Northwestern University, Feinberg School of Medicine, Chicago, IL. matthew.potts@northwestern.edu. 